\title{
Catalyst-Free and Highly Selective N,N-Diallylation of Anilines in Aqueous Phase
}

\author{
Zhengyin Du, Xiaohong Wei, Wenwen Zhang, Yuanmin Zhang, and Qunji Xue \\ Key Laboratory of Eco-Environment-Related Polymer Materials of Ministry of Education, Key Laboratory of Polymer Materials of \\ Gansu Province, College of Chemistry and Chemical Engineering, Northwest Normal University, Lanzhou 730070, China
}

Correspondence should be addressed to Zhengyin Du; clinton_du@126.com

Received 4 June 2012; Revised 15 July 2012; Accepted 23 July 2012

Academic Editor: Ana Moldes

Copyright (C) 2013 Zhengyin Du et al. This is an open access article distributed under the Creative Commons Attribution License, which permits unrestricted use, distribution, and reproduction in any medium, provided the original work is properly cited.

A highly selective diallylation reaction of anilines with allyl bromide was achieved in aqueous alcohol solution in the presence of potassium carbonate and without the use of any catalyst. The reaction tolerates a wide range of functionalities, and various tertiary amines were obtained in the yield of up to $99 \%$ with complete conversion of anilines.

\section{Introduction}

$\mathrm{N}$-alkylation of aniline derivatives is an important reaction in organic synthesis, which has been widely applied in the preparation of dyes, fluorescence probes, agrochemicals, and pharmaceuticals [1]. The challenge of this reaction is to obtain excellent selectivity for mono- or dialkylation products and to avoid the formation of corresponding quaternary ammonium salts from N,N-dialkylaryl amines. Many methods have been reviewed for the synthesis of substituted amines [2, 3]. However, they are still suffering some problems, such as the use of toxic reagents [4] and the control of the selectivity of mono- and dialkylation-aniline derivatives [5]. In order to overcome these problems, noble metal complexes and salts involving $\mathrm{Ru}[6], \mathrm{Ir}[7,8], \mathrm{Pt}[9], \mathrm{Au}[10,11]$, and $\mathrm{Pd}$ $[12,13]$ as catalysts and alcohols as alkylating agents have been reported extensively in homogeneous phase. Transition metal-free protocols have also been described, although they normally require harsh reaction conditions, such as high temperatures and pressures, to achieve reasonable yields of products [14]. Compared to homogeneous catalysts, heterogeneously catalysed methodologies based on $\mathrm{Ra}-\mathrm{Ni}$ [15] and magnetite [16] have been proposed as alternatives to prepare monoalkylation products. Recently, microwave irradiation has been proved to be efficient for the syntheses of $\mathrm{N}$-alkyl anilines [17]. However, they all suffered from high temperatures and long reaction times. Moreover, the dialkylation products were not involved or were only byproducts in the previously mentioned literatures.

In recent years, Ju and Varma $[18,19]$ disclosed direct generation of tertiary amines by $\mathrm{N}$-alkylation reaction of amines with alkyl halides in aqueous phase under microwave irradiation. But the alkylations focused mainly on the reactions of secondary amines with alkyl halides and primary amines with dihaloalkanes. The ionic liquid $\mathrm{BMImPF}_{6}$ and silica were also reported to improve the N,N-bisallylation of amines with allyl bromide [20,21]. But the conversion of most of substrates is very low, the selectivity of diallylation products is poor, and the needed reaction time is long. Besides, few of literatures were reported for bisallylation reaction of anilines. Therefore, it is necessary to make great efforts on the preparation of N,N-diallylanilines derivatives by one-step diallylation of anilines.

As a basis of this investigation, we report herein onestep diallylation of anilines by allyl bromide in mildly basic aqueous media to afford a series of N,N-diallylanilines in a simple and straightforward manner (Scheme 1).

\section{Experimental}

A mixture of aniline $(0.5 \mathrm{mmol})$, allyl bromide $(1.5 \mathrm{mmol})$, potassium carbonate $(2 \mathrm{mmol})$, ethanol $(2 \mathrm{~mL})$, and water $(1 \mathrm{~mL})$ was added to a $50 \mathrm{~mL}$ round flask and stirred at 
TABLE 1: Optimization of the reaction conditions of aniline with allyl bromide ${ }^{\mathrm{a}}$.

\begin{tabular}{|c|c|c|c|c|c|c|}
\hline \multirow{2}{*}{ Entry } & \multirow{2}{*}{ Base (mmol) } & \multirow{2}{*}{ Temp $\left({ }^{\circ} \mathrm{C}\right)$} & \multirow{2}{*}{ Solvent (mL) } & \multirow{2}{*}{ Time (h) } & \multicolumn{2}{|c|}{ Yield $(\%)^{b}$} \\
\hline & & & & & $\mathbf{2 a}[22]$ & $3 a[22]$ \\
\hline 1 & None & 70 & $\mathrm{C}_{2} \mathrm{H}_{5} \mathrm{OH}(3)$ & 5.5 & 14 & 32 \\
\hline 2 & $\mathrm{Na}_{2} \mathrm{CO}_{3}(2)$ & 70 & $\mathrm{C}_{2} \mathrm{H}_{5} \mathrm{OH}(3)$ & 5.5 & 54 & 16 \\
\hline 3 & $\mathrm{NaHCO}_{3}(2)$ & 70 & $\mathrm{C}_{2} \mathrm{H}_{5} \mathrm{OH}(3)$ & 5.5 & 59 & Trace \\
\hline 4 & $\mathrm{~K}_{2} \mathrm{CO}_{3}(2)$ & 70 & $\mathrm{C}_{2} \mathrm{H}_{5} \mathrm{OH}(3)$ & 5.5 & 86 & Trace \\
\hline 5 & $\mathrm{~K}_{2} \mathrm{CO}_{3}(1.5)$ & 70 & $\mathrm{C}_{2} \mathrm{H}_{5} \mathrm{OH}(3)$ & 5.5 & 65 & 8 \\
\hline 6 & $\mathrm{~K}_{2} \mathrm{CO}_{3}(2.5)$ & 70 & $\mathrm{C}_{2} \mathrm{H}_{5} \mathrm{OH}(3)$ & 5.5 & 74 & Trace \\
\hline 7 & $\mathrm{~K}_{2} \mathrm{CO}_{3}(2)$ & RT & $\mathrm{C}_{2} \mathrm{H}_{5} \mathrm{OH}(3)$ & 7 & 35 & 35 \\
\hline 8 & $\mathrm{~K}_{2} \mathrm{CO}_{3}(2)$ & 40 & $\mathrm{C}_{2} \mathrm{H}_{5} \mathrm{OH}(3)$ & 6.5 & 68 & 31 \\
\hline 9 & $\mathrm{~K}_{2} \mathrm{CO}_{3}(2)$ & 70 & $\mathrm{C}_{2} \mathrm{H}_{5} \mathrm{OH} / \mathrm{H}_{2} \mathrm{O}(2 / 1)$ & 2 & 86 & Trace \\
\hline 10 & $\mathrm{~K}_{2} \mathrm{CO}_{3}(2)$ & 70 & $\mathrm{C}_{2} \mathrm{H}_{5} \mathrm{OH} / \mathrm{H}_{2} \mathrm{O}(1 / 1)$ & 2 & 49 & 19 \\
\hline 11 & $\mathrm{~K}_{2} \mathrm{CO}_{3}(2)$ & 70 & $\mathrm{C}_{2} \mathrm{H}_{5} \mathrm{OH} / \mathrm{H}_{2} \mathrm{O}(1 / 2)$ & 2 & 57 & 4 \\
\hline 12 & $\mathrm{~K}_{2} \mathrm{CO}_{3}(2)$ & 70 & $\mathrm{H}_{2} \mathrm{O}(3)$ & 2 & 30 & 23 \\
\hline
\end{tabular}

${ }^{\mathrm{a}}$ Reaction conditions: aniline $(0.5 \mathrm{mmol})$, allyl bromide $(1.5 \mathrm{mmol})$, and TLC detection.

${ }^{\mathrm{b}}$ Isolated yield by column chromatography. The products are known and characterised thoroughly by NMR, IR, MS, and elemental analysis, which were consistent with literature data.

TABLE 2: Effect of the amount of allyl bromide on the reaction ${ }^{\mathrm{a}}$.

\begin{tabular}{lccc}
\hline Entry & 1a/allyl bromide $(\mathrm{mmol})$ & $\mathbf{2 a}(\%)^{\mathrm{b}}$ & \\
\hline 1 & $1: 2$ & 27 & 30 \\
2 & $1: 2.4$ & 86 & 30 \\
3 & $1: 3$ & 86 & Trace \\
4 & $1: 3.6$ & Trace \\
\hline${ }^{\mathrm{a}}$ Reaction conditions: aniline $(0.5 \mathrm{mmol}), \mathrm{K}_{2} \mathrm{CO}_{3}(2 \mathrm{mmol}), \mathrm{C}_{2} \mathrm{H}_{5} \mathrm{OH}(2 \mathrm{~mL}), \mathrm{H}_{2} \mathrm{O}(1 \mathrm{~mL}), 70^{\circ} \mathrm{C}, 2$ hours. & \\
${ }^{\mathrm{b}}$ Isolated yield. & &
\end{tabular}

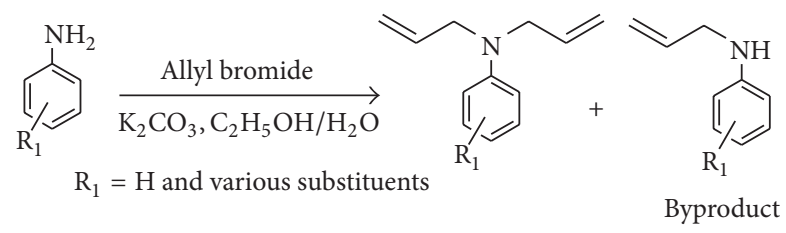

Scheme 1: One-step diallylation of anilines.

$70^{\circ} \mathrm{C}$ for the desired time until complete consumption of starting material as judged by TLC. Then, the reaction mixture was condensed by evaporation of solvents under reduced pressure and was washed with saturated sodium carbonate solution and poured into a separating funnel. The content was extracted with ethyl acetate $(10 \mathrm{~mL} \times 3)$, and the combined organic layers were dried over anhydrous magnesium sulfate. The solvent was removed by evaporation under reduced pressure to afford the crude products, which were further purified by column chromatography on silica gel using petroleum ether and ethyl acetate as the eluents.

Physical spectroscopic data of new product: $\mathrm{N}$-allyl-4chloro-2-nitrobenzenamine (3p): yellowish crystal; Mp: 49$50^{\circ} \mathrm{C} ;{ }^{1} \mathrm{H}$ NMR $\left(400 \mathrm{MHz}, \mathrm{CDCl}_{3}, \mathrm{ppm}\right) \delta 3.93\left(s, 2 \mathrm{H}, \mathrm{CH}_{2}\right)$, $4.76(s, 1 \mathrm{H}), 5.24-5.34\left(m, 2 \mathrm{H},=\mathrm{CH}_{2}\right), 5.90-5.99(m, 1 \mathrm{H}$,
$\mathrm{CH}), 6.38(d, J=8.0 \mathrm{~Hz}, 1 \mathrm{H}, \mathrm{NH}), 7.44-7.50(m, 2 \mathrm{H}, \mathrm{Ar}-$ $\mathrm{H}) ;{ }^{13} \mathrm{C}$ NMR $\left(100 \mathrm{MHz}, \mathrm{CDCl}_{3}, \mathrm{ppm}\right) \delta 147.8,144.3,133.2$, 129.3, 125.2, 117.31, 111.8, 105.5 (all unsaturated $\mathrm{CH}$ ), 45.8 $\left(\mathrm{CH}_{2}\right) ; \mathrm{MS}$ (EI) $m / z(\%): 212,185,177$ (100), 165, 139, 131, 77; IR $\left(\mathrm{KBr}, v / \mathrm{cm}^{-1}\right)$ : $3394(\mathrm{NH}), 1616(\mathrm{C}=\mathrm{C}), 1532,1344(\mathrm{C}-\mathrm{N})$, 805, 734; Anal. calcd for $\mathrm{C}_{9} \mathrm{H}_{9} \mathrm{ClN}_{2} \mathrm{O}_{2}(212.04)$ : C, 50.84; $\mathrm{H}$, 4.27; found: $\mathrm{C}, 50.72 ; \mathrm{H}, 4.10$.

\section{Results and Discussion}

To begin our study, a standard reaction between aromatic amines and allyl bromide was carried out under different reaction conditions. The reaction of commercial available and inexpensive aniline (1a) with allyl bromide was chosen as a model under catalyst-free conditions. The reaction progress was detected by TLC until aniline disappeared completely (Table 1). When aniline reacted with excess of allyl bromide in the absence of any base in ethanol at $70^{\circ} \mathrm{C}$, the desired product N,N-diallylaniline (2a) was obtained only in $14 \%$ of yield, whereas $\mathrm{N}$-allylaniline (3a) was a major product with the yield of $32 \%$ (Table 1, entry 1). Subsequently, various bases were investigated for this reaction. Poor selectivity and low yield of $2 \mathbf{a}$ were observed in the presence of $\mathrm{Na}_{2} \mathrm{CO}_{3}$ and $\mathrm{NaHCO}_{3}$ (Table 1, entries 2 and 3). However, the good yield of $86 \%$ was achieved, and only trace of $\mathbf{3 a}$ was observed when using $\mathrm{K}_{2} \mathrm{CO}_{3}$ as a base (Table 1, entry 4). The amount 
TABLE 3: Synthesis of N,N-diallylanilines from various anilines and allyl bromide ${ }^{\mathrm{a}}$.

\begin{tabular}{|c|c|c|c|c|c|}
\hline & & Allyl & $\overbrace{2 a-q}$ & & \\
\hline \multirow{2}{*}{$\begin{array}{l}\text { Entry } \\
1\end{array}$} & \multicolumn{2}{|c|}{$\mathrm{R}$ of Anilines } & \multirow{2}{*}{$\frac{\text { Time }(\mathrm{h})}{2}$} & \multicolumn{2}{|c|}{ Yield $(\%)^{\mathrm{b}}$} \\
\hline & $1 \mathrm{a}$ & $\mathrm{H}$ & & $2 \mathbf{a}[22], 86$ & Trace \\
\hline 2 & $1 b$ & $2-\mathrm{CH}_{3}$ & 4 & $2 \mathbf{b}[23], 68$ & Trace \\
\hline 3 & $1 \mathrm{c}$ & $3-\mathrm{CH}_{3}$ & 1 & 2c [24], 96 & $-^{c}$ \\
\hline 4 & $1 d$ & $4-\mathrm{CH}_{3}$ & 1.5 & 2d [23], 98 & $-^{c}$ \\
\hline 5 & le & $2,4-\left(\mathrm{CH}_{3}\right)_{2}$ & 2 & 2e [23], 92 & Trace \\
\hline 6 & 1f & $2-\mathrm{CH}_{3} \mathrm{O}$ & 1.5 & $2 f[23], 91$ & $-^{c}$ \\
\hline 7 & $1 \mathrm{~g}$ & $4-\mathrm{CH}_{3} \mathrm{O}$ & 1 & $2 \mathbf{g}[23], 99$ & $-^{c}$ \\
\hline 8 & $1 \mathrm{~h}$ & $2,5-\left(\mathrm{CH}_{3} \mathrm{O}\right)_{2}$ & 2 & 2h [25], 93 & Trace \\
\hline 9 & $1 \mathrm{i}$ & $3-\mathrm{Cl}$ & 3.5 & $2 \mathbf{i}[25], 76$ & $3 \mathbf{i}[25], 23$ \\
\hline 10 & $\mathbf{1 j}$ & $4-\mathrm{Cl}$ & 3.5 & $2 \mathbf{j}[22], 77$ & $3 \mathbf{j}[22], 10$ \\
\hline 11 & $1 \mathbf{k}$ & $4-\mathrm{Br}$ & 3.5 & $2 \mathbf{k}[20], 78$ & $3 \mathbf{k}[20], 20$ \\
\hline 12 & 11 & $2,5-\mathrm{Cl}_{2}$ & 6 & Trace & 31 [26], 74 \\
\hline 13 & $1 \mathrm{~m}$ & $3-\mathrm{NO}_{2}$ & 5 & $\mathbf{2 m}[26], 80$ & $\mathbf{3 m}$ [27], 15 \\
\hline 14 & $1 n$ & $4-\mathrm{NO}_{2}$ & 6 & Trace & 3n [22], 42 \\
\hline 15 & 10 & $2-\mathrm{NO}_{2}$ & 6 & Trace & $30[28], 38$ \\
\hline 16 & $1 p$ & $4-\mathrm{Cl}-2-\mathrm{NO}_{2}$ & 24 & Trace & $3 \mathbf{p}, 37$ \\
\hline 17 & $1 q$ & $2,4-\mathrm{Cl}_{2}-6-\mathrm{NO}_{2}$ & 24 & NR & \\
\hline
\end{tabular}

Reaction conditions: anilines ( $0.5 \mathrm{mmol})$, allyl bromide $(1.5 \mathrm{mmol}), \mathrm{K}_{2} \mathrm{CO}_{3}(2 \mathrm{mmol}), \mathrm{C}_{2} \mathrm{H}_{5} \mathrm{OH}(2 \mathrm{~mL}), \mathrm{H}_{2} \mathrm{O}(1 \mathrm{~mL}), 70^{\circ} \mathrm{C}$, TLC detection.

${ }^{\mathrm{b}}$ Isolated yield; all known products are characterised thoroughly by NMR, IR, MS, and elemental analysis, which were consistent with literature data.

${ }^{\mathrm{c}}$ Not observed.

of potassium carbonate was further examined and found that 4 equivalents were beneficial to the aimed product (Table 1, entries 4-6). The exploration of this reaction at different temperature revealed that the yield and the selectivity of 2a increased simultaneously with the temperature increase (Table 1, entries 4, 7, and 8). Considering the solubility of $\mathrm{K}_{2} \mathrm{CO}_{3}$ in ethanol is very low, the mixture of ethanol and water was used as reaction medium. It is found that water can affect the alkylation manifestly (Table 1, entries 4 and 9-12). The presence of a small quantity of water in the reaction system is in favour of shortening reaction times and improving the yield and selectivity of $\mathbf{2 a}$. A brief optimization reveals that a mixture of ethanol and water $(2 / 1 \mathrm{~mL})$ is the most suitable medium for the desired transformation, in which aniline can be completely converted to the dialkylation product with the yield of $86 \%$ in 2 hours (Table 1, entry 9).

The molar ratio of aniline and allyl bromide was also optimized. As seen in Table 2, the ratio affected the reaction significantly. The best yield of N,N-diallylaniline was obtained when 3 equivalents of allyl bromide relative to aniline were used (Table 2, entry 3 ).

In this regard, the direct diallylation reactions of various substituted anilines were explored under the above optimized conditions, and the results are listed in Table 3. From this Table, it can be seen that the electronic and steric hindrance effects of substituents affect the reaction time and the yield of aimed product significantly. Anilines with electron-donating substituents, such as methoxy and methyl, were smoothly converted to the corresponding diallylation products in good-to-excellent yield with excellent selectivity (Table 3, entries 1-8). Halogen atom(s) attached on the aromatic ring decreased the yield and selectivity of 2 , as a little of 3 was observed as byproduct (Table 3, entries 9-11). For 2,5-dichloroaniline, trace of the diallylation product was detected, whereas the monoalkylation product was obtained in $74 \%$ of yield (Table 3, entry 12), which might be due to the large steric hindrance of the substrate. The electronwithdrawing substituents, such as nitrogroup, reduced the electron cloud density of nitrogen on amino group, thus reducing the nucleophilicity of anilines. As a result, the diallylation almost could not occur, and only about $40 \%$ of monoallylation products were gained for ortho- and paranitroaniline (Table 3, entries 14-16). It is unexpected that 3 -nitroaniline gave $80 \%$ of N,N-diallylaniline as well as $15 \%$ of N-allylaniline (Table 3, entry 13). This may be the cause of none of hindrance and small effect on the nucleophilicity 
of amino group. 2,4-Dichloro-6-nitroaniline did not react with allyl bromide under the same conditions (Table 3, entry 17). Obviously, it is the result of synergetic effect of steric hindrance and electronic effect of substituents.

\section{Conclusions}

In conclusion, we have developed a direct, green, and highly efficient method for the synthesis of N,N-diallylaniline in aqueous phase under mild conditions. The advantages of this protocol include avoiding the use of any catalyst and toxic organic solvents, complete conversion of anilines, highto-excellent yield and selectivity, short reaction times, and avoiding the overalkylation to form quaternary ammonium salts.

\section{Acknowledgments}

The authors gratefully acknowledge National Natural Science Foundation of China (20702042), Program for Changjiang Scholars and Innovative Research Team in University (IRT1177), Key Laboratory of Polymer Materials of Gansu Province (zd-06-18), and NWNU Young Teachers Research Improving Program (NWNU-LKQN-10-11) for financial support.

\section{References}

[1] S. R. Stauffer and J. F. Hartwig, "Fluorescence resonance energy transfer (FRET) as a high-throughput assay for coupling reactions. Arylation of amines as a case study," Journal of the American Chemical Society, vol. 125, no. 23, pp. 6977-6985, 2003.

[2] R. N. Salvatore, C. H. Yoon, and K. W. Jung, "Synthesis of secondary amines," Tetrahedron, vol. 57, no. 37, pp. 7785-7811, 2001.

[3] M. Johannsen and K. A. Jørgensen, "Allylic amination," Chemical Reviews, vol. 98, no. 4, pp. 1689-1708, 1998.

[4] M. Selva, P. Tundo, and A. Perosa, "Reaction of primary aromatic amines with alkyl carbonates over $\mathrm{NaY}$ faujasite: a convenient and selective access to mono- $N$-alkyl anilines," Journal of Organic Chemistry, vol. 66, no. 3, pp. 677-680, 2001.

[5] C. Chiappe and D. Pieraccini, "Direct mono- $N$-alkylation of amines in ionic liquids: chemoselectivity and reactivity," Green Chemistry, vol. 5, no. 2, pp. 193-197, 2003.

[6] C. Feng, Y. Liu, S. Peng, Q. Shuai, G. Deng, and C. J. Li, "Ruthenium-catalyzed tertiary amine formation from nitroarenes and alcohols," Organic Letters, vol. 12, no. 21, pp. 4888-4891, 2010.

[7] K. I. Fujita, Y. Enoki, and R. Yamaguchi, "Cp" Ir-catalyzed $\mathrm{N}$-alkylation of amines with alcohols. A versatile and atom economical method for the synthesis of amines," Tetrahedron, vol. 64, no. 8, pp. 1943-1954, 2008.

[8] S. Michlik and R. Kempe, "New iridium catalysts for the efficient alkylation of anilines by alcohols under mild conditions," Chemistry, vol. 16, no. 44, pp. 13193-13198, 2010.

[9] S. C. Yang, Y. C. Tsai, and Y. J. Shue, "Direct platinum-catalyzed allylation of anilines using allylic alcohols," Organometallics, vol. 20, no. 25, pp. 5326-5330, 2001.
[10] A. Leyva-Pérez, J. R. Cabrero-Antonino, Á. Cantín, and A. Corma, "Gold(I) catalyzes the intermolecular hydroamination of alkynes with imines and produces $\alpha, \alpha^{\prime}, N$ triarylbisenamines: studies on their use as intermediates in synthesis," Journal of Organic Chemistry, vol. 75, no. 22, pp. 7769-7780, 2010.

[11] L. He, X. B. Lou, J. Ni et al., "Efficient and clean gold-catalyzed one-pot selective $N$-alkylation of amines with alcohols," Chemistry, vol. 16, no. 47, pp. 13965-13969, 2010.

[12] L. L. Hill, J. L. Crowell, S. L. Tutwiler et al., "Synthesis and X-ray structure determination of highly active $\mathrm{Pd}(\mathrm{II}), \mathrm{Pd}(\mathrm{I})$, and $\mathrm{Pd}(0)$ complexes of Di(tert-butyl)neopentylphosphine (DTBNpP) in the arylation of amines and ketones," Journal of Organic Chemistry, vol. 75, no. 19, pp. 6477-6488, 2010.

[13] G. Mora, B. Deschamps, S. Van Zutphen, X. F. Le Goff, L. Ricard, and P. Le Floch, "Xanthene-phosphole ligands: synthesis, coordination chemistry, and activity in the palladiumcatalyzed amine allylation," Organometallics, vol. 26, no. 8, pp. 1846-1855, 2007.

[14] G. Guillena, D. J. Ramón, and M. Yus, "Hydrogen autotransfer in the $\mathrm{N}$-alkylation of amines and related compounds using alcohols and amines as electrophiles," Chemical Reviews, vol. 110, no. 3, pp. 1611-1641, 2010.

[15] J. L. García Ruano, A. Parra, J. Alemán, F. Yuste, and V. M. Mastranzo, "Monoalkylation of primary amines and $N$ sulfinylamides," Chemical Communications, no. 4, pp. 404-406, 2009.

[16] R. Martínez, D. J. Ramón, and M. Yus, "Selective Nmonoalkylation of aromatic amines with benzylic alcohols by a hydrogen autotransfer process catalyzed by unmodified magnetite," Organic and Biomolecular Chemistry, vol. 7, no. 10, pp. 2176-2181, 2009.

[17] G. Marzaro, A. Guiotto, and A. Chilin, "Microwave-promoted mono- $N$-alkylation of aromatic amines in water: a new efficient and green method for an old and problematic reaction," Green Chemistry, vol. 11, no. 6, pp. 774-776, 2009.

[18] Y. Ju and R. S. Varma, "Aqueous $N$-alkylation of amines using alkyl halides: direct generation of tertiary amines under microwave irradiation," Green Chemistry, vol. 6, no. 4, pp. 219-221, 2004.

[19] Y. Ju and R. S. Varma, "An efficient and simple aqueous $\mathrm{N}$-heterocyclization of aniline derivatives: microwave-assisted synthesis of $N$-aryl azacycloalkanes," Organic Letters, vol. 7, no. 12, pp. 2409-2411, 2005.

[20] C. Chiappe, P. Piccioli, and D. Pieraccini, "Selective Nalkylation of anilines in ionic liquids," Green Chemistry, vol. 8, no. 3, pp. 277-281, 2006.

[21] B. Basu, S. Paul, and A. K. Nanda, "Highly selective NAlkylation of amines promoted on silica: an efficient and recyclable surface," Green Chemistry, vol. 11, no. 8, pp. 1115-1120, 2009.

[22] Y. Tao, B. Wang, B. Wang, L. Qu, and J. Qu, "Highly efficient and regioselective allylation with allylic alcohols catalyzed by $\left[\mathrm{Mo}_{3} \mathrm{~S}_{4} \mathrm{Pd}\left(\eta^{3}\right.\right.$-allyl $\left.)\right]$ clusters," Organic Letters, vol. 12, no. 12, pp. 2726-2729, 2010.

[23] N. Li and W. D. Jones, "Mechanistic investigation of the cobaltcatalyzed selective conversion of diallylanilines to quinolines involving $\mathrm{C}-\mathrm{N}$ and $\mathrm{C}-\mathrm{H}$ activations," Journal of the American Chemical Society, vol. 129, no. 35, pp. 10707-10713, 2007.

[24] J. H. Choi, S. H. Hong, and A. D. Towns, "High fastness heterocyclic azo disperse dyes bearing ester functions," Coloration Technology, vol. 115, no. 1, pp. 32-37, 1999. 
[25] G. Bartoli, E. Marcantoni, M. Bosco, and R. Dalpozzo, "Unexpected reactivity of allyl magnesium chloride with nitroarenes. A general method of synthesis of $\mathrm{N}$-allyl- $\mathrm{N}$ arylhydroxylamines and $\mathrm{N}$-allylanilines," Tetrahedron Letters, vol. 29, no. 18, pp. 2251-2254, 1988.

[26] M. Halim, M. S. Tremblay, S. Jockusch, N. J. Turro, and D. Sames, "Transposing molecular fluorescent switches into the near-IR: development of luminogenic reporter substrates for redox metabolism," Journal of the American Chemical Society, vol. 129, no. 25, pp. 7704-7705, 2007.

[27] V. Pace, F. Martínez, M. Fernández, J. V. Sinisterra, and A. R. Alcántara, "Effective monoallylation of anilines catalyzed by supported KF," Organic Letters, vol. 9, no. 14, pp. 2661-2664, 2007.

[28] S. M. S. Chauhan, R. Singh, and G. Geetanjali, "An improved synthesis of $\mathrm{N}$-substituted-2-nitroanilines," Synthetic Communications, vol. 33, no. 16, pp. 2899-2906, 2003. 

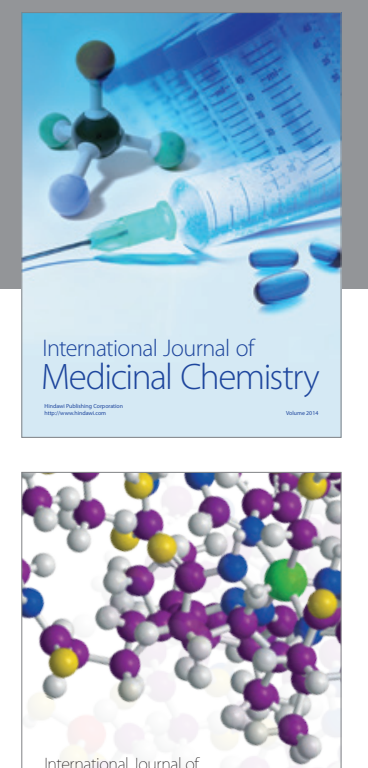

\section{Carbohydrate} Chemistry

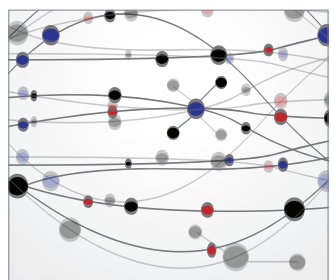

The Scientific World Journal
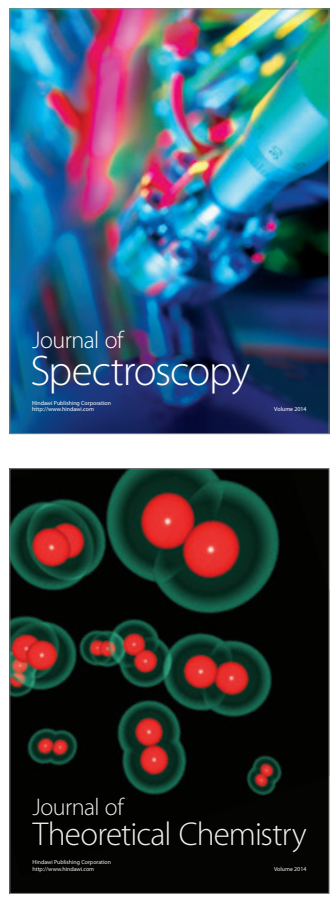
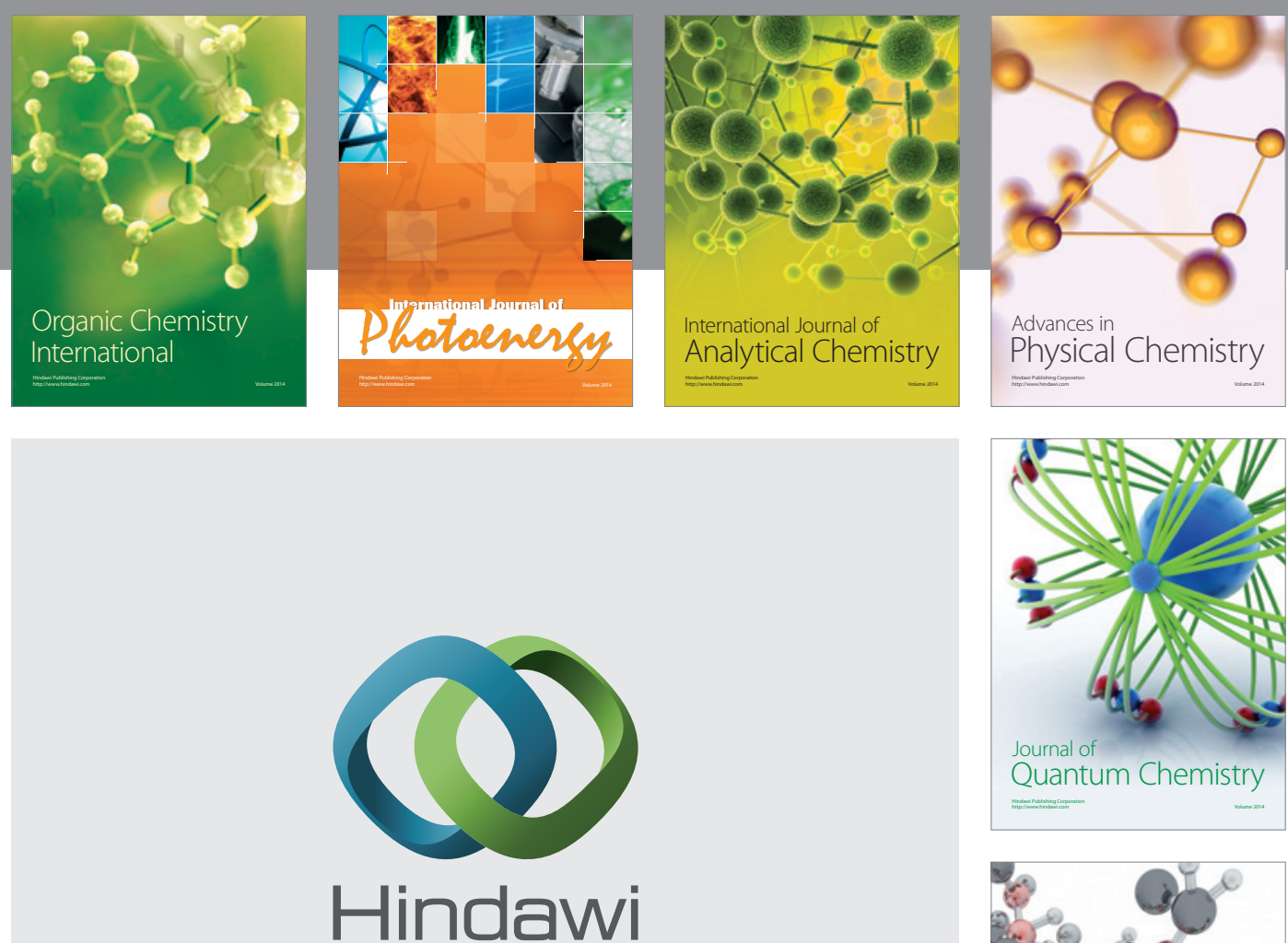

Submit your manuscripts at

http://www.hindawi.com

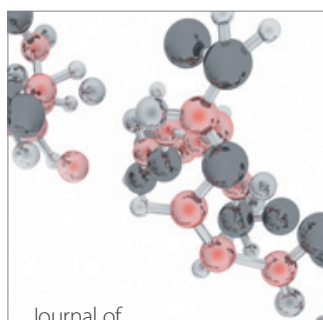

Analytical Methods

in Chemistry

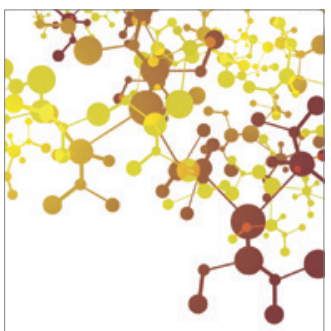

Journal of

Applied Chemistry

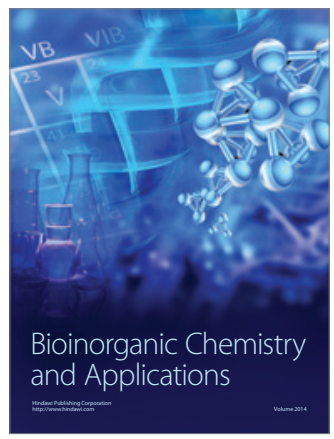

Inorganic Chemistry
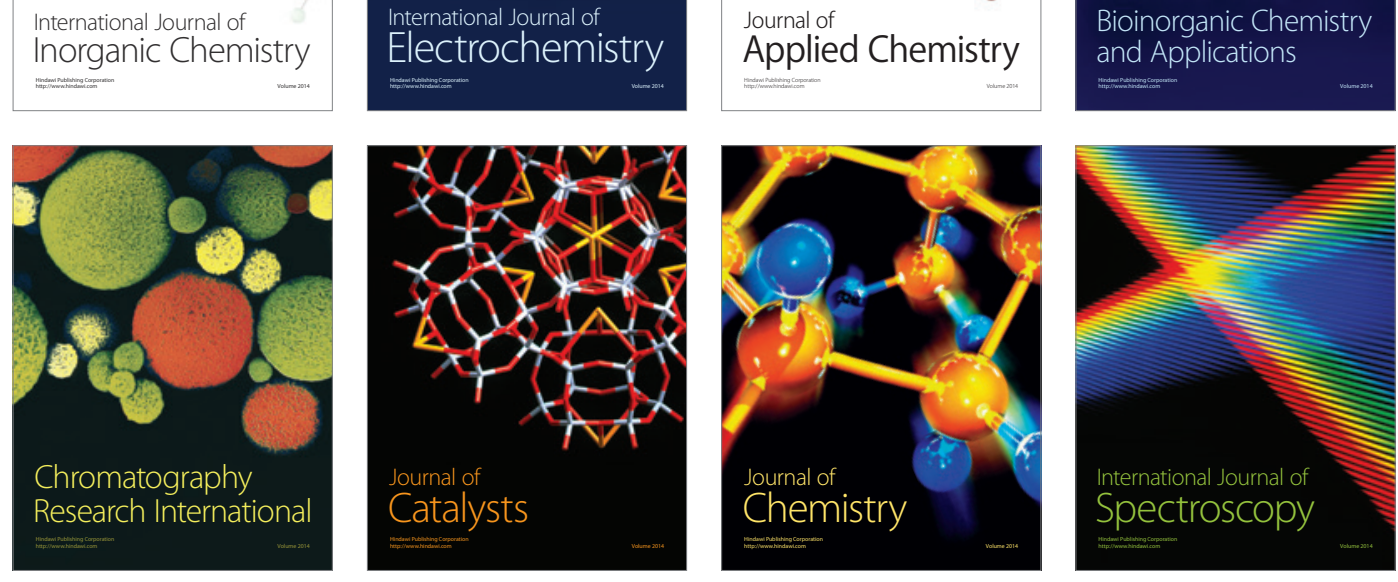